\title{
Well-Differentiated Grade 2, Type 3 Gastrointestinal Neuroendocrine Tumour with Bilateral Metastatic Ovarian Involvement: Report of an Unusual Case
}

\author{
Ray Manneh $^{\mathrm{a}}$ Daniel Castellano $^{\mathrm{a}}$ Oscar Caso $^{\mathrm{b}}$ Carmelo Loinaz $^{\mathrm{b}}$ \\ Jesús Jiménez ${ }^{c}$ Juana Estenoz ${ }^{d} \quad$ Maria Calatayud $^{\mathrm{e}} \quad$ Juan M. Sepúlveda $^{a}$ \\ Rocio García-Carbonero ${ }^{a}$ \\ Departments of ${ }^{\mathrm{a}}$ Medical Oncology, ${ }^{\mathrm{b}}$ General Surgery, ${ }^{\mathrm{C}} \mathrm{Gynecology}$ and Obstetrics, \\ ${ }^{\mathrm{d}}$ Nuclear Medicine and ${ }^{\mathrm{e}}$ Endocrinology, Hospital Universitario 12 de Octubre, \\ Madrid, Spain
}

\section{Key Words}

Gastric cancer - Neoplasm recurrence, local · Neuroendocrine tumors - Somatostatin . Stomach neoplasms

\begin{abstract}
Treatment of metastatic gastric neuroendocrine tumours (NETs) is challenging. In oligometastatic cases, surgical resection is recommended whenever possible. Somatostatin analogues have been used to decrease gastrin levels, and available evidence suggests that these drugs can also reduce recurrences. Here we present a highly unusual case involving a patient with a well-differentiated grade 2, type 3 gastric NET with exclusive metastatic bilateral ovarian involvement. To our knowledge, this is the first such case reported in the literature, as the cause of ovarian involvement is usually due to local invasion rather than metastasis. We believe this case is of interest not only due to the unusual presentation, but also because it makes us consider adjuvant treatment with somatostatin analogues in patients with lowgrade tumours and a positive postoperative octreoscan.

(C) 2016 The Author(s)


Manneh et al.: Well-Differentiated Grade 2, Type 3 Gastrointestinal Neuroendocrine Tumour with Bilateral Metastatic Ovarian Involvement: Report of an Unusual Case

\section{Introduction}

Gastric neuroendocrine tumours (NETs) account for more than 20\% of all diagnosed gastric tumours [1]. In recent years, the incidence of these tumours has increased substantially, probably due to an increase in the number and quality of diagnostic tests [2]. These tumours can be classified into three main types according to their clinical and histological characteristics. The most common are type 1 tumours (accounting for $70-80 \%$ of all gastric NETs), which present with achlorhydria-induced hypergastrinemia secondary to chronic atrophic gastritis and are commonly associated with $\mathrm{B}_{12}$ malabsorption and pernicious anemia. Most type 1 NETs are grade 1 (G1), with metastasis present in only $2-5 \%$ of patients at diagnosis. Type 2 tumours are the least common (5-6\% of gastric NETs) and are sporadic tumours associated with Zollinger-Ellison's syndrome or, more commonly, related to type 1 multiple endocrine neoplasms (MEN-1 syndrome). Type 3 gastric NETs are sporadic, often solitary, and usually higher-grade lesions (G3 being the most common). Type 3 NETs, unlike types 1 and 2, are not associated with elevated gastrin levels. They are typically larger lesions, may be ulcerated, and are capable of inducing carcinoid syndrome (producing 5hydroxytryptophan). Metastases are present at diagnosis in more than $50 \%$ of type 3 gastric NETs.

Treatment of metastatic gastric NETs is highly complex, and a multidisciplinary approach is considered essential to assure that all therapeutic options are considered. In oligometastatic cases, NCCN and ENETS guidelines recommend surgical resection whenever possible [3, 4]. Somatostatin analogues have been used to decrease gastrin levels, and there is evidence to suggest that use of these drugs can also reduce recurrences [5-8].

Here we present a highly unusual case involving a patient diagnosed with a welldifferentiated G2, type 3 gastric NET with exclusive metastatic bilateral ovarian involvement. To our knowledge, this is the first such case reported in the literature, as the cause of ovarian involvement is usually due to local invasion in the context of patients with major abdominal involvement rather than metastasis.

\section{Case Presentation}

A 35-year-old HPV-18-postive female, without any previous personal or family medical history of interest, underwent a routine follow-up examination for cervicitis in December 2013. The gynaecological examination revealed a high-grade squamous intraepithelial lesion. A cone biopsy was performed, and a diagnosis of early infiltrating cervical adenocarcinoma was made. The maximum tumour thickness was $0.7 \mathrm{~mm}$ extending $2 \mathrm{~mm}$ horizontally and adjacent to an in situ adenocarcinoma ( $5 \mathrm{~mm}$ in the largest diameter) located $2 \mathrm{~mm}$ from the upper border of the endocervix. The clinical stage was pT1A2.

Given these findings, together with the fact that the patient was nulligravida but with reproductive desires, a radical trachelectomy plus sentinel node biopsy was planned. In accordance with established protocol, pelvic magnetic resonance imaging was performed (January 2014) prior to surgery, revealing a solid, slightly heterogeneous lesion in the right ovary measuring $27 \times 24 \mathrm{~mm}$ and an intracapsular lesion $(10 \mathrm{~mm} \times 8 \mathrm{~mm})$ in the left ovary. Radiologically, both lesions were suggestive of ovarian leiomyomas. No pathological findings were observed at the cervical level, and no evidence of lymphadenopathy was observed.

Given these highly unusual radiological findings - bilateral involvement of the ovaries due to leiomyomas - the multidisciplinary tumour board recommended a biopsy of both ovaries. A bilateral ovarian laparoscopy (January 29,2014) revealed a solid 25-mm lesion in 
Manneh et al.: Well-Differentiated Grade 2, Type 3 Gastrointestinal Neuroendocrine

Tumour with Bilateral Metastatic Ovarian Involvement: Report of an Unusual Case

the right ovary and a 15-mm lesion in the left ovary. Based on the pathological examination of the intraoperative biopsy, the preliminary finding was a 'right ovarian cyst with areas of carcinoma'. Consequently, trachelectomy was ruled out and instead a right adnexectomy was performed. Postoperatively, the patient progressed well without complications. The definitive pathological findings were an infiltrating low-grade NET tumour (Ki-67 $=5 \%)$ of likely gastrointestinal origin.

Complementary diagnostic tests included a colonoscopy (negative) and a gastroscopy. The gastroscopy revealed a tumour measuring approximately $4 \mathrm{~cm}$ in diameter with central ulceration located in the greater curvature of the stomach. The biopsy revealed a welldifferentiated, non-gastrin-producing G2 NET (Ki-67 = 7\%). In addition to the endoscopic tests, somatostatin receptor scintigraphy (octreoscan) and 18FDG-positron emission tomography (18FDG-PET/CT) were performed to assess disease dissemination: both tests revealed pathological uptake in the body-fundus junction, in the gastrohepatic lymph nodes, and in the left ovary. Gastrin levels were normal. Chromogranin levels were $105 \mathrm{ng} / \mathrm{ml}$, while urinary 5-hydroxyindoleacetic acid (5-HIAA) levels were $21 \mathrm{mg} /$ day. No relevant biochemical alterations were detected. Fig. 1 and fig. 2 show the results of the ${ }^{18}$ FDG-PET/CT scans.

Based on these findings, the case was presented to the multidisciplinary NET board, summarized as follows: 35-year-old female with a history of endocervical microinfiltrating adenocarcinoma leading to an incidental diagnosis of a well-differentiated G2 gastric NET with metastatic nodal involvement in a single locoregional area with bilateral involvement of the ovaries, treated previously with right adnexectomy. Given the patient's young age and lack of comorbidities, the tumour board - following clinical guidelines - recommended surgical treatment of the affected structures (left ovary, stomach, and gastrohepatic lymph nodes). In late March 2014, a complete laparoscopic gastrectomy was performed, with esophagojejunal anastomosis and D1 lymphadenectomy expanded to include nodal stations 7-9. No complications arose during the postoperative period.

The postoperative pathological report showed the following: complete gastrectomy with a well-differentiated G2 NET invading the entire gastric wall into the serosa, with metastasis in 1 out of 17 dissected nodes. On immunohistochemistry, the tumour was positive for AE1AE3, chromogranin, synaptophysin, $\mathrm{CDX}-2$, and negative for gastrin. Given these findings, the case was again presented to the tumour board, which recommended left adnexectomy. Consequently, a laparoscopic hysterectomy with left adnexectomy was performed in May 2014 without complications. In the postoperative period, the patient progressed favourably with acceptable gastrointestinal tolerance except for clinical signs of occasional dumping. Pathological findings from the surgical specimens indicated metastasis in the left ovary from a well-differentiated G2 tumour, no evidence of disease in the uterus, and foci of mild dysplasia in the endocervix.

After both surgeries, a thoracoabdominal-pelvic CT and an octreoscan (fig. 3) were performed in June 2014, with image fusion. The images showed that the patient was free of macroscopic disease, and laboratory results for chromogranin A and 5-HIAA acid levels were normal. In July 2014, the patient had recovered from both surgeries and was in good general condition with tolerable symptoms associated with early onset menopause and total gastrectomy (occasional episodes of dumping in addition to hot flushes).

Currently, the patient is free of disease, with excellent performance status (100\%). Regular follow-up examinations are scheduled to monitor her condition. 
Manneh et al.: Well-Differentiated Grade 2, Type 3 Gastrointestinal Neuroendocrine Tumour with Bilateral Metastatic Ovarian Involvement: Report of an Unusual Case

\section{Discussion}

The case reported here involves a young woman with an incidental diagnosis of a type 3, G2 gastric NET with bilateral ovarian involvement reminiscent of Krukenberg's tumour, which is typical in gastric adenocarcinomas [9]. At present, the route of spread from the stomach to the ovaries in such cases is not well understood, although diverse mechanisms have been postulated, including lymphatic dissemination (case reports have described gastric adenocarcinomas confined to the mucosae with lymphatic infiltration and ovarian metastases), and haematogenic or peritoneal dissemination $[10,11]$.

Gastroscopy is the main diagnostic and follow-up technique in patients with a gastric NET. Ultrasound-guided endoscopy is indicated to assess the extent of gastric wall invasion. For full staging, thoracoabdominal-pelvic CT and octreoscan are recommended [12].

The present case was managed in accordance with published guidelines, which recommend surgical treatment of oligometastatic disease whenever possible [3, 4]. After surgery, the patient was free of disease, and we elected to perform active surveillance with regular CT and octreoscans. We did not administer any adjuvant treatment in this case because the current evidence does not support the use of adjuvant therapy in patients without postsurgical evidence of disease.

Gastric NETs should be managed in a center with an experienced multidisciplinary team that can offer the patient a full range of therapeutic alternatives. Although progress has been made in the systemic treatment of advanced NETs in recent years, systemic treatment options remain limited $[5,6]$.

\section{Conclusion}

The case presented here is the first such case described in the literature. Other reported cases are mostly in the context of very advanced disease in which curative-intent surgery is not feasible. In this case, surgery was successful without the need for systemic therapy. However, in patients with a positive octreoscan following surgery, adjuvant treatment with somatostatin analogues may be beneficial in low-grade tumours such as the one reported here. However, more studies are needed to confirm this approach.

\section{Acknowledgements}

The authors wish to thank Bradley Londres for his assistance in translating and editing the text, and Ipsen Pharma S.A. for providing funding for these services.

\section{Statement of Ethics}

Written informed consent was obtained from the patient for publication of this case report and any accompanying images. A copy of the written consent is available for review by the Editor of this journal. 
Manneh et al.: Well-Differentiated Grade 2, Type 3 Gastrointestinal Neuroendocrine Tumour with Bilateral Metastatic Ovarian Involvement: Report of an Unusual Case

\section{Disclosure Statement}

The authors report no conflicts of interest and there are no competing interests. The translation and editing of the manuscript was funded by Ipsen Pharma S.A., who also paid for the article processing charges related to publication.

\section{References}

1 Pericleous M, Toumpanakis C, Lumgair H, Caplin ME, Morgan-Rowe L, Clark I, Luong TV: Gastric mixed adenoneuroendocrine carcinoma with a trilineage cell differentiation: case report and review of the literature. Case Rep Oncol 2012;5:313-319.

-2 Yao JC, Hassan M, Phan A, Dagohoy C, Leary C, Mares JE, Abdalla EK, Fleming JB, Vauthey J-N, Rashid A, Evans DB: One hundred years after 'carcinoid': epidemiology of and prognostic factors for neuroendocrine tumors in 35,825 cases in the United States. J Clin Oncol 2008;26:3063-3072.

-3 Strosberg J, Nasir A, Cragun J, Gardner N, Kvols L: Metastatic carcinoid tumor to the ovary: a clinicopathologic analysis of seventeen cases. Gynecol Oncol 2007;106:65-68.

-4 Pavel M, Grossman A, Arnold R, Perren A, Kaltsas G, Steinmüller T, de Herder W, Nikou G, Plöckinger U, Lopes JM, Sasano H, Buscombe J, Lind P, O’Toole D, Oberg K; Palma de Mallorca Consensus Conference Participants: ENETS consensus guidelines for the management of brain, cardiac and ovarian metastases from neuroendocrine tumors. Neuroendocrinology 2010;91:326-332.

5 Rinke A, Müller H-H, Schade-Brittinger C, Klose K-J, Barth P, Wied M, Mayer C, Aminossadati B, Pape U-F, Bläker M, Harder J, Arnold C, Gress T, Arnold R; PROMID Study Group: Placebo-controlled, double-blind, prospective, randomized study on the effect of octreotide LAR in the control of tumor growth in patients with metastatic neuroendocrine midgut tumors: a report from the PROMID Study Group. J Clin Oncol 2009;27:4656-4663.

-6 Caplin ME, Pavel M, Ćwikła JB, Phan AT, Raderer M, Sedláčková E, Cadiot G, Wolin EM, Capdevila J, Wall L, Rindi G, Langley A, Martinez S, Blumberg J, Ruszniewski P: Lanreotide in metastatic enteropancreatic neuroendocrine tumors. N Engl J Med 2014;371:224-233.

7 Manfredi S, Pagenault M, de Lajarte-Thirouard A-S, Bretagne J-F: Type 1 and 2 gastric carcinoid tumors: long-term follow-up of the efficacy of treatment with a slow-release somatostatin analogue. Eur J Gastroenterol Hepatol 2007;19:1021-1025.

8 Sidéris L, Dubé P, Rinke A: Antitumor effects of somatostatin analogs in neuroendocrine tumors. Oncologist 2012;17:747-755.

-9 Baba Y, Ishikawa S, Ikeda K, Honda S, Miyanari N, Iyama K-I, Baba H: A patient with 43 synchronous early gastric carcinomas with a Krukenberg tumor and pericardial metastasis. Gastric Cancer 2007;10:135-139.

10 Kakushima N, Kamoshida T, Hirai S, Hotta S, Hirayama T, Yamada J, Ueda K, Sato M, Okumura M, Shimokama T, Oka Y: Early gastric cancer with Krukenberg tumor and review of cases of intramucosal gastric cancers with Krukenberg tumor. J Gastroenterol 2003;38:1176-1180.

11 NCCN Clinical Practice Guidelines in Oncology: Neuroendocrine Tumors. Version 2.2014. NCCN.org.

-12 Delle Fave G, Kwekkeboom DJ, Van Cutsem E, Rindi G, Kos-Kudla B, Knigge U, Sasano H, Tomassetti P, Salazar R, Ruszniewski P; Barcelona Consensus Conference participants: ENETS Consensus Guidelines for the management of patients with gastroduodenal neoplasms. Neuroendocrinology 2012;95:74-87. 


\section{Case Reports in Oncology}

\begin{tabular}{l|l}
\hline Case Rep Oncol 2016;9:255-261 \\
\hline DOI: 10.1159/000445940 & $\begin{array}{l}\text { C 2016 The Author(s). Published by S. Karger AG, Basel } \\
\text { www.karger.com/cro }\end{array}$ \\
\hline
\end{tabular}

Manneh et al:: Well-Differentiated Grade 2, Type 3 Gastrointestinal Neuroendocrine Tumour with Bilateral Metastatic Ovarian Involvement: Report of an Unusual Case

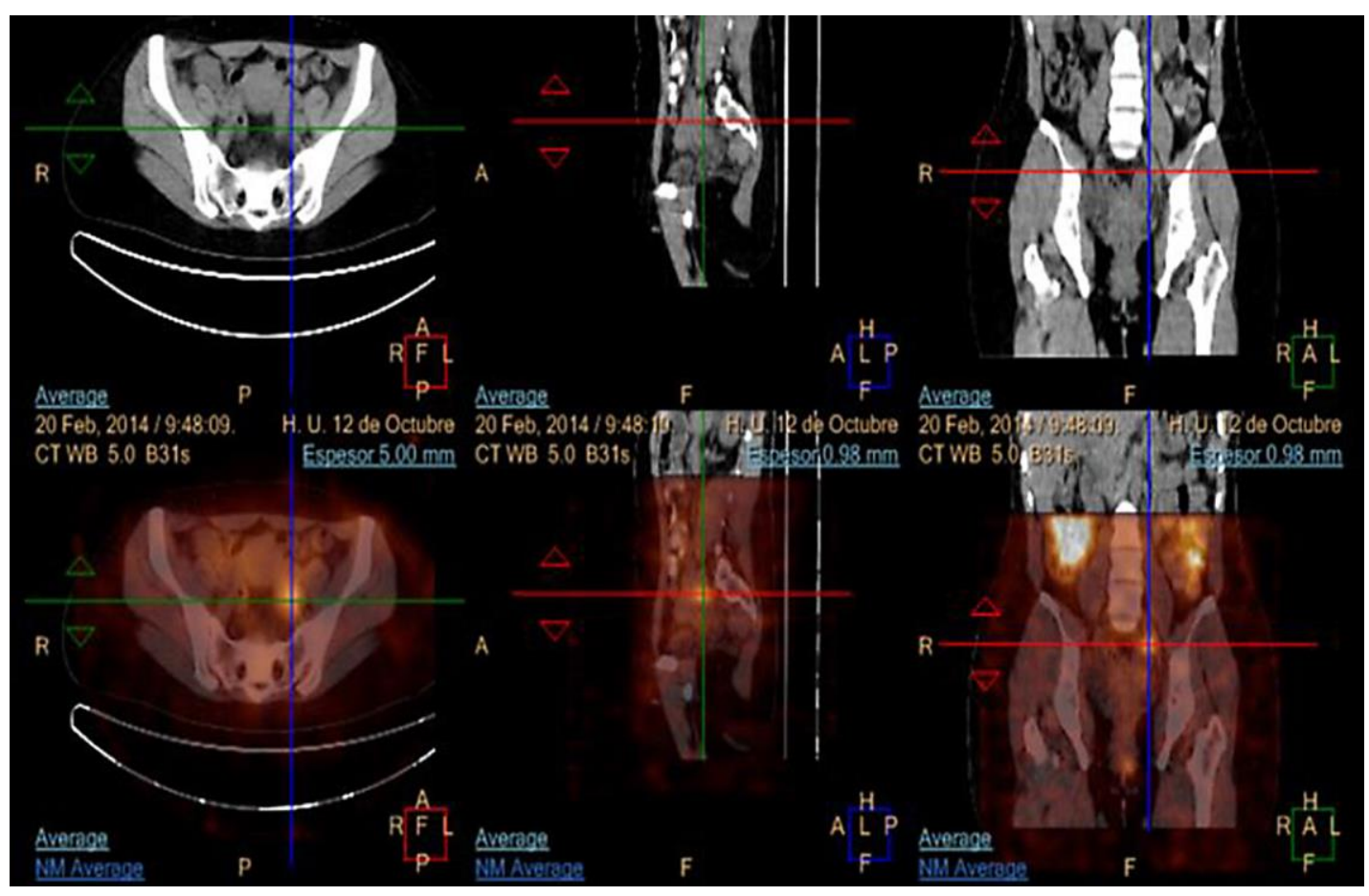

Fig. 1. ${ }^{18}$ FDG-PET/CT depicting the left ovarian lesion. $\operatorname{SUVmax}=4.7$.

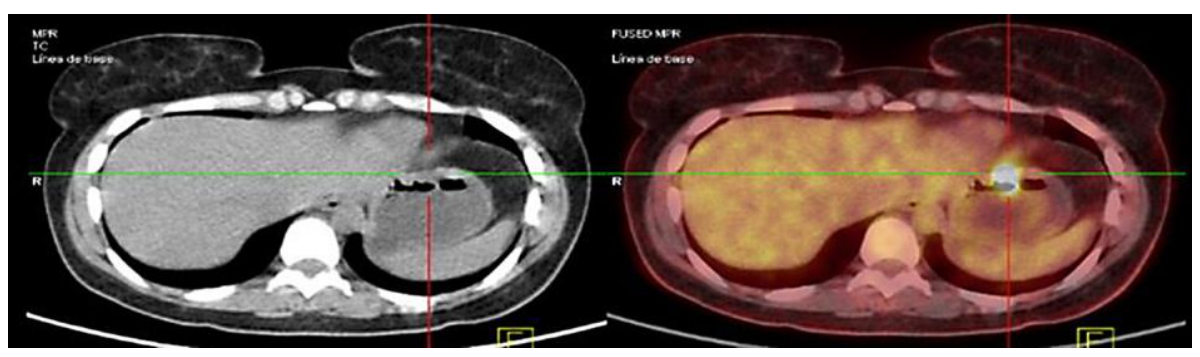

Fig. 2. ${ }^{18 F D G-P E T / C T ~ s h o w i n g ~ t h e ~ g a s t r i c ~ m a s s . ~ S U V m a x ~}=11.2$. 


\section{Case Reports in Oncology}

Case Rep Oncol 2016;9:255-261

DOI: $10.1159 / 000445940$

(c) 2016 The Author(s). Published by S. Karger AG, Basel www.karger.com/cro

Manneh et al.: Well-Differentiated Grade 2, Type 3 Gastrointestinal Neuroendocrine

Tumour with Bilateral Metastatic Ovarian Involvement: Report of an Unusual Case

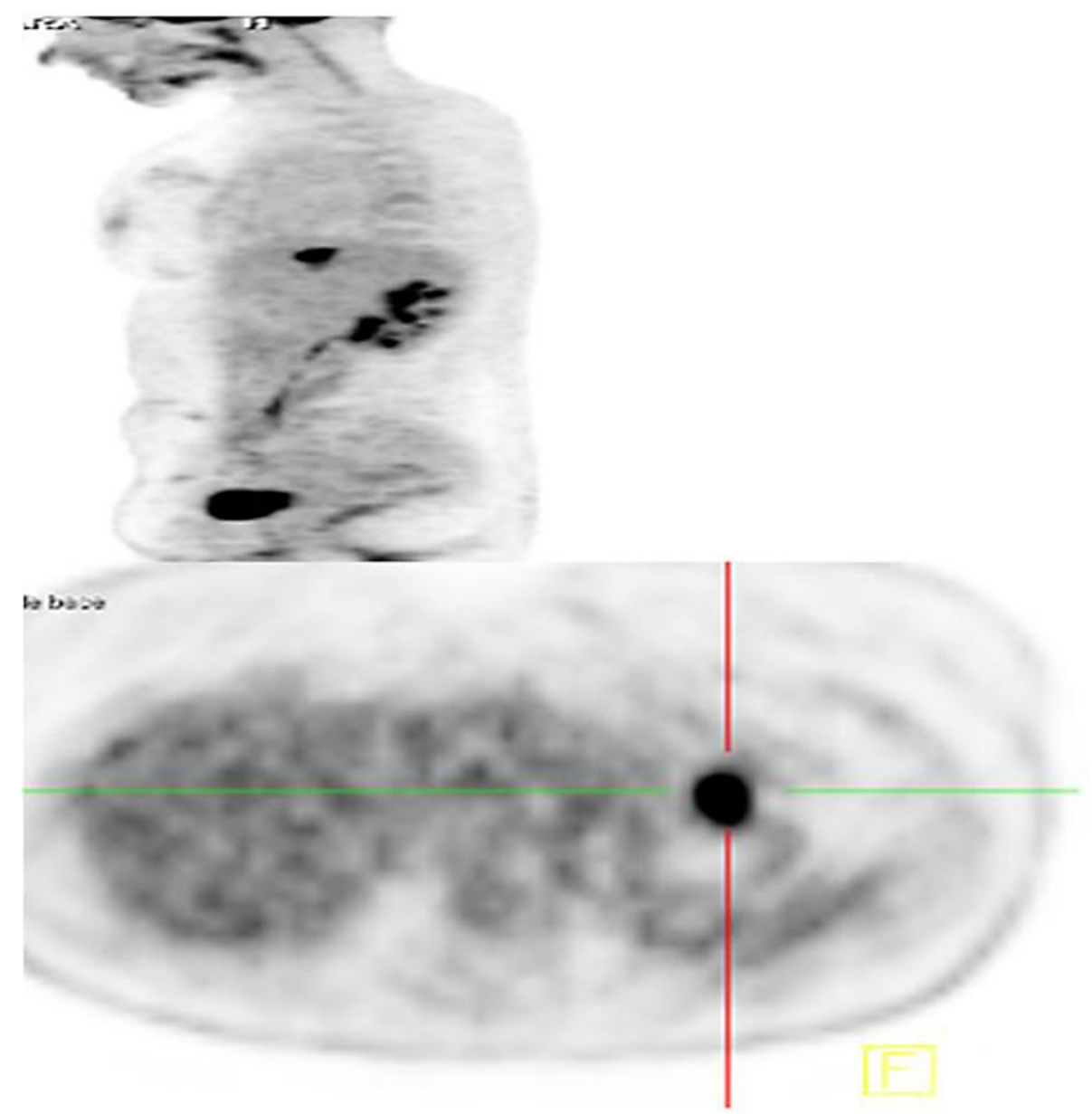

Fig. 3. Octreoscan showing the gastric mass (top image) and ovarian lesion (bottom image). 